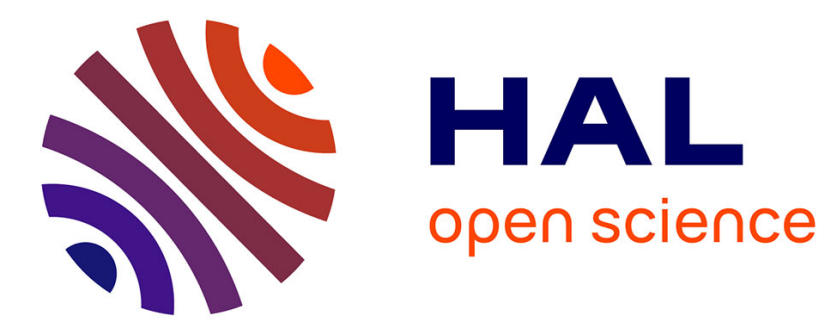

\title{
Does Tracking Shape the Intergenerational Transmission of Educational Attainment? Evidence from Switzerland
} Jean Marc Falter, Florian Wendelspiess Chávez Juárez, Giovanni Ferro-Luzzi

\section{To cite this version:}

Jean Marc Falter, Florian Wendelspiess Chávez Juárez, Giovanni Ferro-Luzzi. Does Tracking Shape the Intergenerational Transmission of Educational Attainment? Evidence from Switzerland. 2012. halshs-00771941

\section{HAL Id: halshs-00771941 \\ https://shs.hal.science/halshs-00771941}

Preprint submitted on 24 Jan 2013

HAL is a multi-disciplinary open access archive for the deposit and dissemination of scientific research documents, whether they are published or not. The documents may come from teaching and research institutions in France or abroad, or from public or private research centers.
L'archive ouverte pluridisciplinaire HAL, est destinée au dépôt et à la diffusion de documents scientifiques de niveau recherche, publiés ou non, émanant des établissements d'enseignement et de recherche français ou étrangers, des laboratoires publics ou privés. 


\title{
Does Tracking Shape the Intergenerational Transmission of Educational Attainment? Evidence from Switzerland
}

\author{
Jean-Marc Falter* \\ Florian Wendelspiess Chávez Juárez* \\ Giovanni Ferro-Luzzi ${ }^{\dagger}$
}

August 31, 2012

\begin{abstract}
The Swiss schooling system is characterized by early tracking of pupils into different types of education, which suggests that the impact of parental background may affect transitions at a relatively young age which condition the future transitions of their children as well as their final educational attainment. In this study, we investigate the impact of family background variables on schooling outcomes at upper secondary level by means of a two-stage estimation model. Our empirical specification enables us to take into account the cumulative impact of parental variables on tracking and on upper secondary school achievement. As expected, favourable family background attributes are positively correlated with school outcomes at all stages but we show that parental effects remain important at higher grade levels, even with early selection through tracking and after controlling for cognitive ability. These findings are especially relevant for girls and should help policymakers in designing equal opportunity tracking schemes, especially at young ages.
\end{abstract}

Keywords: Schooling transition, tracking, family background, bivariate ordered probit, Switzerland

JEL-Classification: I21, J62, E24

\footnotetext{
${ }^{*}$ Leading House in Economics of Vocational Education/Department of Economics, University of Geneva.

${ }^{\dagger}$ Department of Economics, University of Geneva and Centre for Research on Education, Geneva. Corresponding author: giovanni.ferro-luzzi@unige.ch.
} 


\section{Introduction}

Children's parental background undoubtedly plays a major role in explaining educational inequality as more educated parents get more educated children. Yet, the whole process behind children's educational attainment is complex and the observed correlations between parental and children's education clearly reflect various mechanisms at work. As pointed out by several authors (see for instance Behrman and Rosenzweig (2002)), it is not so easy to disentangle the various effects of family, culture, individual ability as well as personal history on educational attainment which are at the core of the ubiquitous nature vs. nurture debate.

According to the biological argument, ability is transmitted from parents to children and able children get more education. This leads to more able parents being better educated and giving birth to more able children, who in turn naturally receive more education. At the other extreme, children with highly educated parents simply benefit from more educational resources which allows them to grow better educated. Finally, as shown by Solon (2004), the extent of intergenerational correlation between parents' and children's educational attainements heavily depends on the institutional environnment. Each of these transmission channels call for specific policy prescriptions, which may well have different effects on the equity and efficiency of the educational system. A better understanding of the mechanisms behind the intergenerational transmission of education is therefore of upmost importance.

This paper contributes to the literature by focusing on the impact of family background variables on education attainment at the upper secondary level in Switzerland. Switzerland is a particularly interesting country to study for many reasons. First, it presents the highest impact of parental socioeconomic status on educational outcome of children across 31 participating countries in the PISA program (OECD, 2002; Zahner Rossler, 2005). Second, Switzerland presents interesting institutional features such as early tracking and widespread vocational education. Early tracking is often blamed for the high level of schooling inequality in Switzerland (OECD (2009)). These aspects allow investigating the impact of parental background variables on transitions taking place at different point in the educational path as young people (or their parents) have to make important choices about their future at a relatively young age. Presumably, parental background variables may have a great impact at time of tracking, which may in turn affect highest educational attainment. We therefore make use of a two-stage estimation model in order to isolate the effect of parental characteristics on tracking and upper secondary education. We use a unique dataset from Switzerland combining educational skill measures at the lower secondary education level with detailed information on the transition to upper secondary education.

The model is estimated separately for male and female students in order to uncover possible differences in the way parental background affects the tracking and educational outcome of 
children. Our results suggest that indeed there are important differences between girls and boys. While common pattern can be observed, we detect differences in the impact of family background variables on the second stage i.e. to upper secondary educational attainment. For girls, parental background variables mostly affect educational outcomes through transitions occurring between the age 15 and 19, while for boys part of the parental background impact stems from the tracking which occured earlier in the educational path.

\section{Transitions in education and family background}

The correlation between parental education, family background and children's educational attainment is a widely analyzed topic ${ }^{1}$. Some studies provide a rather descriptive view of intergenerational mobility such as Sen and Clemente (2010) who depict intergenerational correlations in education using data from Canada or Schütz et al. (2008) who perform a cross-country analysis of the importance of family background variables on school outcomes. Another strand of the literature focuses more on the causal link between parental education and individual outcomes, by trying to disentangle between nature and nurture. Such studies rely on specific research instruments such as monozygotic twins, adoptees or instrumental variables (see the comprehensive and critical survey of these methods by Holmund et al. (2011)). While our study attempts to control for ability, our estimates of intergenerational correlations are a composite of both unobserved attributes and inequality of opportunities.

Studies by Dustmann (2004) and Lauer (2003) are more closely connected to our research. The former investigates the impact of parental background on upper secondary school choices over time in Germany and the impact of this correlation on wages. He shows that parental background, through their effect on upper secondary schooling, explain important wage differences on the labor market. Lauer (2003) uses a similar model to the one employed in this study and applies it to German and French data. An important finding that motivates the use of such a model in this context is that the correlation between secondary schooling outcome and postschooling outcome seems to be positive, which makes the use of a simultaneous equations model necessary. Regarding intergenerational transmission of education she finds as well a positive impact of parental education and occupation on the schooling outcome of children. However, lack of information on ability could also induce an upward bias to the estimates.

A growing literature focuses more specifically on Switzerland. Cattaneo et al. (2007) document the changes over time of the intergenerational correlation in educational attainment, providing evidence of greater educational opportunities for women with lowly educated parents. Bauer and Riphahn (2006) and Bauer and Riphahn (2007) take advantage of interesting features of Switzerland i.e. early tracking and the high rate of immigrants. They use census data in a

\footnotetext{
${ }^{1}$ See the recent survey from (Black and Devereux, 2011).
} 
standard ordered probit model and find that cantons with relatively early children selection in the different schooling tracks tend to have lower intergenerational mobility. Their results also point to substantial differences in the intergenerational education transmission across population groups. Finally, Falter et al. (2011) focus on upper secondary education and measure the impact of intergenerational links at age 15 on wages. As transitions rates to tertiary education used to be substantially lower in Switzerland than in Germany, transitions at age 15 matter less for wage inequality in Switzerland than in Germany. Yet, the recent expansion of tertiary education may change the picture in Switzerland.

The present study contributes to the above literature by using data which enable us to control for educational skill and to a lesser extent for effort. This also enables us to estimate inequality of opportunity sources closer to the propositions by Roemer (1998), who distinguishes inequality due to different opportunities from inequality due to different effort and ability levels. Our paper also contributes to the literature on tracking. We move away from measuring the impact of tracking on educational attainment or inequality ${ }^{2}$ and look instead at how tracking may shape intergenerational links. Increasing the age of tracking, a policy that is often recommended (see OECD (2009)), would have a limited impact on educational inequality if parental background still matters after tracking takes place.

\subsection{The Swiss education system}

Before entering a somewhat more detailed explanation of the chosen approach, a short description of the Swiss education system is in order. A first and and significant feature is its decentralization across 26 different cantonal systems. Cantons all follow general common guidelines but use slightly different systems ${ }^{3}$. During the first years of mandatory schooling, pupils all share the same class irrespective of their level. The first tracking occurs after four to six years depending on the canton. Typically, children are sorted into three main tracks in the lower secondary school: pre-gymnasial, extended requirements and basic requirements. Some cantons use two or four tracks, while some others even make use of integrated and cooperative tracks. Next, upper secondary education splits into Matura schools (preparing pupils for university), specialized middle schools (no direct access to university) and apprenticeship (vocational education and training). Bridge packages in the form of additional schooling years or basic vocational training are also available for students not able or not willing to apply directly to upper secondary education. Vocational training and specialized middle schools can be complemented by a "professional A-level" which gives access to universities of applied science. ${ }^{4}$ Three

\footnotetext{
${ }^{2}$ See international evidence from Hanushek and Woessman (2006); the impact of tracking on higher education has been investigated by van Elk et al. (2011)

${ }^{3}$ Detailed information can be found on www.edk.ch or EDK (2009).

${ }^{4}$ Maturité professionelle in French.
} 
large transitions are observed in this system. The major transition is from primary to lower secondary school and generally corresponds to the first tracking. The second transition takes place between lower and upper secondary education, which also corresponds to the transition between mandatory and post-compulsory schooling. The final main transition is from upper secondary to tertiary education and/or the labor market. In this paper, we focus on the first two transitions, which are schematically represented in Figure 1.

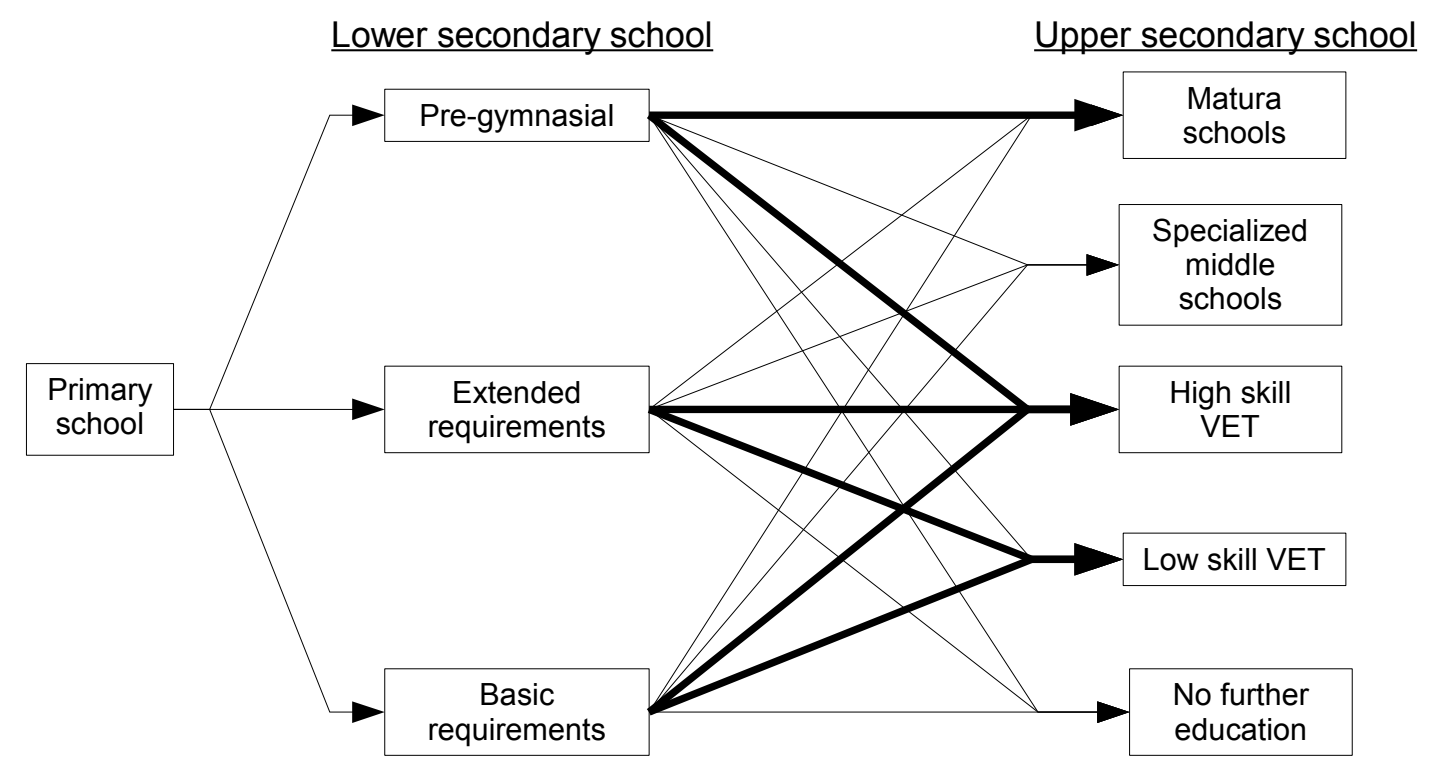

Note: For each track the two most frequently observed patterns are illustrated with bold arrows

Figure 1: Scheme transitions

The transitions are represented by arrows going from one track to the others. The two most frequently observed pattern for each lower secondary track are indicated with bold arrows. There are no legal restriction to any combination of tracking, but in some cases additional exams are needed for upward mobility (EDK, 2009). Nevertheless it is quite obvious that the track in the upper secondary education is not fully independent from the lower secondary education one, since this would fundamentally question the very purpose of tracking in the latter level. In section 5.1 we present the detailed transition matrix for the lower to upper secondary schooling transition.

\subsection{Direct and indirect effects of family background}

The main question we attempt to answer is the following: At what moment and through which channel do family background characteristics affect educational outcomes and generate potential inequalities of opportunity? As previously mentioned, simply estimating the correlation between final educational outcome and family background variables would most likely overestimate the relationship, due to a possible ability bias. We could only estimate a general correlation or at 
best a total effect. Hence, it would remain unclear at what moment such circumstances play a role and which policy measures could reduce this dependence.

We here focus on upper secondary educational achievements (namely post-mandatory schooling). For many people, this is a crucial choice since they will need to decide on whether to follow a completely school-based education or change to a partly or completely firm-based education. Our goal is to identify the determinants of this decision and its subsequent outcome. This identification of such factors and in both transitions becomes truly challenging when considering not implausibly that they will play a role in both stages, and how to disentangle them.

One could naively try to explain the relative odds of choosing a specific track by relating track choices to family background variables. This, however, would only give us a total effect of these variables on the whole educational process and not on the transition of interest. We therefore need a more precise strategy. We first define the indirect effect as the one affecting schooling decisions prior to the transition of interest. An example would be parents registering their children in pre-gymnasial school which will turn out to also affect the transition after mandatory schooling. In contrast, the direct effect is taking place when the same variable affects the observed transition net of all its prior indirect effects. Obviously, direct and direct effects add up to a total effect. In other words, the determinants of the first transition might influence the second transition as well, directly or indirectly through the outcome of the first transition.

One could even go further and consider the case of direct and indirect effects with opposite signs. For a sound educational policy design, it is important to break down the total impact of a variable into its direct and indirect effects, since the magnitude of the two effects can be tuned by the timing of tracking for example. While the indirect effect in our case builds up during primary school, the direct effect plays a role only after the first tracking and during the lower secondary school.

\section{The econometric model}

As mentioned in the previous section, the main issue is the estimation of direct and indirect effects of the determinants on schooling decisions. Since both have similar determinants, an analysis that would just relate these circumstances with the outcome, would simply estimate the total effects. Such total effects would suffer the shortcomings of other studies that do not control for ability bias (see Cameron and Heckman (1998)). Moreover, such a procedure would leave out the typically sequential nature of educational outcomes. To address these issues, we base our estimation strategy on a two step procedure.

Since pupils students are already sorted into different tracks during the lower secondary education, we must take this sequential tracking into account. Our dependent variables are the 
ordered categorical variables corresponding to the outcomes of the different tracks in Figure 1. The exact definition of our dependent and independent variables will be given in section 4 . We use a bivariate ordered probit model to estimate the effect of family background, individual effects and institutional aspects on the transition from lower to upper secondary education ${ }^{5}$. The econometric model can be written as follows:

$$
\begin{aligned}
& E D U C 1_{i}^{*}=X_{i} \beta_{1}+Z_{i} \delta+\varepsilon_{1 i} \\
& E D U C 2_{i}^{*}=X_{i} \beta_{2}+\gamma E D U C 1_{i}^{*}+S_{i} \varphi+\varepsilon_{2 i}
\end{aligned}
$$

where $E D U C 1^{*}$ and $E D U C 2^{*}$ are the underlying latent dependent variables capturing educational outcome in the lower and upper secondary education respectively. $X$ is a vector of explanatory variables that may influence the educational outcome in both periods independently. $Z$ is a vector of variables which are assumed to influence the educational outcome only in the lower but not in the upper secondary level. The precise nature of these variables is discussed in Section 3.1. The vector $S$ contains variables which only affect the transition from lower to upper secondary education, i.e. variables which we assume not to have any plausible indirect effect. $\varepsilon_{1}$ and $\varepsilon_{2}$ are the residual terms capturing unobserved individual heterogeneity. They are assumed to be distributed as bivariate standard normal with a correlation parameter $\rho$. The $\gamma$ parameter captures the effect of the first stage outcome on the second stage outcome and is crucial since it links the two stages with indirect effects.

For any regressor $X_{j}$, we have three possible effects. $\beta_{1 j}$ and $\beta_{2 j}$ are the direct effects of regressor $X_{j}$ on $E D U C 1$ and EDUC2 respectively, whereas $\beta_{2 j}+\gamma \beta_{1 j}$ captures the total effect of regressors $X_{j}$ on $E D U C 2$. Since a better education in the lower secondary schooling is bound to facilitate the transition to higher subsequent education, we expect the $\gamma$ parameter to be positive. Note that the estimated direct effect $\beta_{1}$ is actually the total effect of all direct and indirect effects prior to the first tracking. This does not constitute a problem in our context, since our interest only lies in the second transition.

The log likelihood function of the model runs as follows (Sjaia, 2008):

$$
\ln \mathcal{L}=\sum_{i=1}^{N} \sum_{j=1}^{3} \sum_{k=1}^{6} I\left(E D U C 1_{i}=j, E D U C 2_{i}=k\right) \cdot \ln \operatorname{Pr}\left(E D U C 1_{i}=j, E D U C 2_{i}=k\right)
$$

where $I\left(E D U C 1_{i}=j, E D U C \mathcal{2}_{i}=k\right)$ is an indicator function taking the value one when both $E D U C 1_{i}=j$ and $E D U C 2_{i}=k$ are true, and zero otherwise.

\footnotetext{
${ }^{5}$ Lauer (2003) uses a similar model for a study on French and German data.
} 


\subsection{Identification}

It is useful to write down the reduced form of the model (leaving out the individual subscript throughout):

$$
\begin{aligned}
& E D U C 1^{*}=X \beta_{1}+Z \delta+\varepsilon_{1} \\
& E D U C 2^{*}=X\left(\beta_{2}+\gamma \beta_{1}\right)+Z \gamma \delta+S \varphi+\varepsilon_{2}
\end{aligned}
$$

The model will be identified and can be estimated if variables in $Z$ that have a direct impact on $E D U C 1$ but not on EDUC2 can be found. While the first condition is easily fulfilled, making sure that the variable has no effect on the second educational outcome is clearly more challenging. Individual determinants must be discarded since they will definitely always have an impact in the second stage if they had one in the first.

Our solution is to take advantage of one specific feature of the Swiss educational system, namely its cantonal heterogeneity, which provides truly exogenous differences that may affect the transitions of pupils during their first transition only. Cantonal fixed effects are not ideal in this respect to identify the model, since they might reflect cultural differences still playing a role in the second stage. For this reason, we focus exclusively on variables describing the educational system in the different cantons. The main instrument we use is the overall share of students in the track with extended requirements, which is essentially based on the way students are tracked after primary school. We supplement this instrument with tracking specific differences across cantons as well as the number of tracks in the lower secondary education. The main instrument (overall share of pupils in the extend requirement track) directly explains the probability of ending up in the upper tracks and it is reasonable to believe that it does not have an impact on the second stage. One might suspect that such a variable is also associated to cultural differences. However Figure 7 shows that the geographical distribution of this variable does not suggest any particular pattern. For example, both cantons of Fribourg and Nidwalden have substantially different proportions of pupils in the extend requirement track compared to their neighbors, but one can hardly think of them as being culturally distinct. Additionally, comparing the share of students in the extended requirements tracks to the average PISA score in the canton (Figure 8) shows that the differences are not due to different educational skill levels across cantons. Finally, Figure 9 displays the relationship between the share of labor market participants with the matura degree and the share of students in the track with extended requirements. The correlation coefficient is not significantly different from zero, suggesting that our instrument has no relationship with the second stage outcome. Besides these visual and conceptual justifications of our instrument, we also provide test statistics of joint significance of the instruments in the first stage. 


\subsection{Estimating direct and direct effects}

This bivariate ordered probit model is very handy to estimate the direct and indirect effect of regressors presented in section 2.2. The computation of the direct and indirect effects with respect to the latent underlying variables is straightforward. The direct effect of a regressor is given by $\beta_{2}$ and the indirect effect by $\gamma \beta_{1}$, with the total effect simply given by their sum. Note that our specification allows for opposite direct and indirect effects, which is the case whenever $\operatorname{sign}\left(\gamma \beta_{1}\right) \neq \operatorname{sign}\left(\beta_{2}\right)$. Two extreme cases can be imagined:

Case 1: A determinant only has a direct impact on the first transition and none on the second, but the latter depends on the outcome of the first transition: $\beta_{1} \neq 0, \beta_{2}=0$ and $\gamma \neq 0$.

Case 2: A determinant only has a direct impact on both transitions, but there is no indirect effect, so that the second transition outcome does not depend on the first outcome at all, but only on the same determinant as in the first transition: $\beta_{1} \neq 0, \beta_{2} \neq 0$ and $\gamma=0$.

The estimated coefficients from an ordered probit model are not directly interpretable, which makes it necessary to compute direct and indirect marginal effects ${ }^{6}$. The probability of a given pair of educational outcomes is given by

$$
\begin{aligned}
\operatorname{Pr}\left(E D U C 1_{i}=j, E D U C 2_{i}=k\right) & =\operatorname{Pr}\left(\mu_{1 j-1}<E D U C 1^{*} \leq \mu_{1 j}, \mu_{2 k-1}<E D U C 2^{*} \leq \mu_{1 k}\right) \\
& =\Phi_{2}\left(\mu_{1 j}-x_{1 i}^{\prime} \beta_{1},\left(\mu_{2 k}-\gamma x_{1 i}^{\prime} \beta_{1}-x_{2 i}^{\prime} \beta_{2}\right) \zeta, \tilde{\rho}\right) \\
& -\Phi_{2}\left(\mu_{1 j}-x_{1 i}^{\prime} \beta_{1},\left(\mu_{2 k-1}-\gamma x_{1 i}^{\prime} \beta_{1}-x_{2 i}^{\prime} \beta_{2}\right) \zeta, \tilde{\rho}\right) \\
& -\Phi_{2}\left(\mu_{1 j-1}-x_{1 i}^{\prime} \beta_{1},\left(\mu_{2 k}-\gamma x_{1 i}^{\prime} \beta_{1}-x_{2 i}^{\prime} \beta_{2}\right) \zeta, \tilde{\rho}\right) \\
& +\Phi_{2}\left(\mu_{1 j}-x_{1 i}^{\prime} \beta_{1},\left(\mu_{2 k-1}-\gamma x_{1 i}^{\prime} \beta_{1}-x_{2 i}^{\prime} \beta_{2}\right) \zeta, \tilde{\rho}\right)
\end{aligned}
$$

where $\Phi_{2}$ is the bivariate standard normal cumulative distribution function, the $\mu$ 's represent the estimated thresholds of the ordered probit model and $\zeta=\frac{1}{1+2 \gamma \rho+\gamma^{2}}$

Since we are mainly interested in the outcome of the second stage, we can simplify this expression by integrating over all possible outcomes of the first stage:

$$
\operatorname{Pr}\left(E D U C 2_{i}=k \mid E D U C 1\right)=\Phi\left(\left(\mu_{2 k}-\gamma x_{1 i}^{\prime} \beta_{1}-x_{2 i}^{\prime} \beta_{2}\right) \zeta\right)-\Phi\left(\left(\mu_{2 k-1}-\gamma x_{1 i}^{\prime} \beta_{1}-x_{2 i}^{\prime} \beta_{2}\right) \zeta\right)
$$

We can then derive the expression for the marginal probabilities

$$
\frac{\partial \operatorname{Pr}\left(E D U C 2_{i}=k \mid E D U C 1\right)}{\partial x_{1 i}}=\gamma \zeta \beta_{1}\left[\phi\left(\left(\mu_{2 k}-\gamma x_{1 i}^{\prime} \beta_{1}-x_{2 i}^{\prime} \beta_{2}\right) \zeta\right)-\phi\left(\left(\mu_{2 k-1}-\gamma x_{1 i}^{\prime} \beta_{1}-x_{2 i}^{\prime} \beta_{2}\right) \zeta\right)\right]
$$

$$
\frac{\partial \operatorname{Pr}\left(E D U C 2_{i}=k \mid E D U C 1\right)}{\partial x_{2 i}}=\zeta \beta_{2}\left[\phi\left(\left(\mu_{2 k}-\gamma x_{1 i}^{\prime} \beta_{1}-x_{2 i}^{\prime} \beta_{2}\right) \zeta\right)-\phi\left(\left(\mu_{2 k-1}-\gamma x_{1 i}^{\prime} \beta_{1}-x_{2 i}^{\prime} \beta_{2}\right) \zeta\right)\right]
$$

\footnotetext{
${ }^{6}$ See Greene (2008).
} 
where equation (9) is the indirect effect though $x_{1}$ and equation (10) refers to the direct effect. Note that for dummy variables, the computation is slightly different, since we compute the expected probability for both possible values and then take the difference in probabilities to get the marginal probability (Sjaia, 2008).

The use of this model has several advantages. We can take into account the endogeneity of previous education in the upper secondary education attainment as highlighted by Lauer (2003). We exploit information from the PISA score at the end of the first stage, which greatly reduces the ability bias as highlighted by Behrman and Rosenzweig (2002). Note however, that the ability bias might still be present in the estimation of the first stage equation, where all effects are confounded. This shortcoming is due to the structure of the data, since no such information is available for the period before the first stage. On the other hand, the ability and effort measures enable us to estimate inequality of opportunity in the spirit of Roemer (1998) for the second stage. All family background variables which have a direct effect in the second stage can be attributed to inequalities of opportunity as we control for the other two inequality sources mentioned by Roemer (1998).

\section{Data}

The data we use in this study come from the Transitions to Education and Employment Survey (TREE), a follow-up of the Swiss PISA 2000 sample, which surveyed students at the age of 15. This is a unique database as it combines variables available in the standard PISA survey with longitudinal information. PISA enables us to gather information on parental background and provides us with a proxy measure of ability, namely the PISA test score. In this paper, we focus on reading scores as it is the only measure covering all students in the data. Information from PISA corresponds to lower secondary education while the follow up survey covers transitions to upper secondary education.

Our first-stage dependent variable is the track in the lower secondary education taking three different values. This information comes directly from the PISA survey. The dependent variable for the second stage is drawn from the follow-up surveys available in TREE. We focus on obtained diploma, since it not only captures the choice made by students but also the success they had. We consider all upper secondary diplomas obtained until the year 2007, which corresponds to seven years after the end of the lower secondary education. The diplomas are classified as an ordinal variable. The bottom outcome is not (yet) having achieved any diploma after seven years. The second and third groups consist of people who have finished a low skilled and high skilled apprenticeship respectively but without a professional matura. For the distinction between low- and high-skilled VET we follow Stalder (2005), who sorts over 100 apprenticeships 


\begin{tabular}{|c|c|c|}
\hline Variable & Stage & Measured concept \\
\hline \multicolumn{3}{|l|}{ Dependent variables } \\
\hline$E D U C 1$ & first & $\begin{array}{l}\text { Ordinal discrete variable for the lower secondary education situation, } \\
\text { where } 1=\text { basic requirements, } 2=\text { extended requirements and } 3= \\
\text { pre-gymnasial }\end{array}$ \\
\hline$E D U C 2$ & second & $\begin{array}{l}\text { Ordinal discrete variable for the upper secondary diploma, where } 1= \\
\text { no diploma, } 2=\text { low skilled VET without PM, } 3=\text { high skilled VET } \\
\text { without PM, } 4=\text { interm. school without PM, } 5=\mathrm{PM} \text { and } 6=\text { Matura }\end{array}$ \\
\hline \multicolumn{3}{|c|}{ Family background variables } \\
\hline Rural areas & both & Dummy variable for rural areas \\
\hline Latin Switzerland & both & $\begin{array}{l}\text { Dummy variable for the French and Italian speaking region of Switzer- } \\
\text { land }\end{array}$ \\
\hline Parental education & both & $\begin{array}{l}\text { Dummy variable taking the value of } 1 \text { if the highest parental education } \\
\text { level corresponds to ISCED-X }\end{array}$ \\
\hline Books & both & Dummy variables capturing the number of books at home \\
\hline Born in $\mathrm{CH}$ & both & $\begin{array}{l}\text { Dummy variable taking the value of one if the child was born in Switzer- } \\
\text { land }\end{array}$ \\
\hline \multicolumn{3}{|c|}{$\underline{\text { Individual characteristics }}$} \\
\hline Female & both & Dummy for women \\
\hline First born & both & Dummy variable for the first born \\
\hline Siblings & both & Counting variable for the number of siblings in the family \\
\hline Absence index & second & PISA composite variable measuring absence at school \\
\hline Effort index & second & PISA composite variable measuring effort at school \\
\hline PISA score & second & Standardized PISA 2000reading scores \\
\hline Private school & second & Dummy for private school students (lower secondary) \\
\hline \multicolumn{3}{|l|}{ Institutional aspects } \\
\hline Wshare* & second & Relative share of jobs is a specific sector (available for 8 sectors) \\
\hline Institutions & first & $\begin{array}{l}\text { Set of dummy variables to capture institutional differences in the edu- } \\
\text { cation systems }\end{array}$ \\
\hline Prop. extended & first & $\begin{array}{l}\text { Proportion of students in the higher rated tracks of the lower secondary } \\
\text { education by canton }\end{array}$ \\
\hline
\end{tabular}

Table 1: Variable description

according to their intellectual requirements ${ }^{7}$. For the sake of clarity, we bypass the details of this classification and consider apprenticeships classified as level 5 and 6 by Stalder as being high-skilled and levels 1 to 4 as low-skilled. The next higher outcome includes graduates of specialized middle schools without professional matura. The second highest group is made up of students with a professional matura from a VET or specialized middle schools. Graduates from matura schools form the top group from the academic track.

\footnotetext{
${ }^{7}$ Bertschy et al. (2009) also uses this classification with the TREE data to approximate the intellectual level of occupations.
} 
The set of explanatory variables we use can be broken down into three groups: family background variables, individual characteristics and institutional factors. The family background variables are mostly taken from the original PISA data. One important variable is the highest level of parental education, measured on the ISCED scale, from which we draw dummy variables for the top three levels. We also use a dummy variable to identify first generation migrants. Additionally some geographic control variables for rural areas and for the non-German part of Switzerland are included.

The set of personal characteristics includes gender, birth rank among siblings, the number of siblings and the PISA reading scores measured in 2000. To simplify the interpretation of the results we standardize the PISA scores to a mean zero and unit standard deviation distribution. We also use two composite indices proposed by PISA to measure effort and students' absenteeism from school. Finally a dummy variable for students from private schools is also included.

As discussed in section 3.1, we introduce a set of variables which enable us to identify the model. This set includes the proportion of pupils in the tracks with extended requirements observed at the cantonal level as well as dummy variables capturing the organization of tracks at the lower secondary school by cantons.

In the second stage, we control for some labor market effects by including the relative importance of 8 economic sectors in terms of jobs with respect to the active population. Table 1 summarizes the whole set of variables and a note pertaining to their their use in the first and/or the second stage.

The original PISA sample available in TREE includes 6'343 students, while reliable information on the obtained diploma is only available for 4'728 students. After deletion of observations due to missing data in the explanatory variables, we end up with a sample of 2'710 students composed of 1'498 girls and 1'212 boys.

\section{Empirical results}

\section{$5.1 \quad$ Descriptive evidence}

Some descriptive statistics are worth discussing. Table 2 presents the proportions of the highest earned upper secondary degree for each lower secondary track.

The reported figures indicate a clear link between lower secondary tracks and upper secondary education. Only about $14 \%$ of pupils from the basic lower secondary school achieve one of the two possible matura, while the proportion is over $80 \%$ for pupils from pre-gymnasial lower secondary schools. At other end, the proportion of students coming from pre-gymnasial schools who end up with no upper secondary diploma is about $5 \%$ with a threefold proportion for basic track students. Two extreme mechanisms could explain the links between these two schooling periods. Firstly, the determinants behind the tracking in the first period are the same as 
Highest obtained upper secondary diploma

\begin{tabular}{lrrrrrr}
\cline { 2 - 6 } & none & $\begin{array}{r}\text { Low skill } \\
\text { VET }\end{array}$ & $\begin{array}{r}\text { High skill } \\
\text { VET }\end{array}$ & Interm. & $\begin{array}{r}\text { Prof. } \\
\text { matura }\end{array}$ & $\begin{array}{r}\text { Acad. } \\
\text { Matura }\end{array}$ \\
Track & & & & & \\
\hline Basic requirements & $18.23 \%$ & $43.74 \%$ & $20.60 \%$ & $3.65 \%$ & $12.04 \%$ & $1.74 \%$ \\
Extended require- & $7.89 \%$ & $16.69 \%$ & $20.81 \%$ & $9.56 \%$ & $26.34 \%$ & $18.71 \%$ \\
ments & & & & & & \\
Pre-gymnasial & $5.19 \%$ & $2.71 \%$ & $5.07 \%$ & $5.07 \%$ & $12.29 \%$ & $69.67 \%$ \\
Total & $9.41 \%$ & $18.41 \%$ & $15.61 \%$ & $6.72 \%$ & $18.41 \%$ & $31.44 \%$ \\
\hline
\end{tabular}

Table 2: Bivariate distribution of educational level based on 2'710 observations.

the ones for upper secondary education, but the two transitions are independent. Secondly, the determinants in the first period do not have an impact on the second transition, but the outcome of the first transition directly determines the second transition. A combination of these two extreme assumptions is clearly possible and very likely to reflect the actual situation.

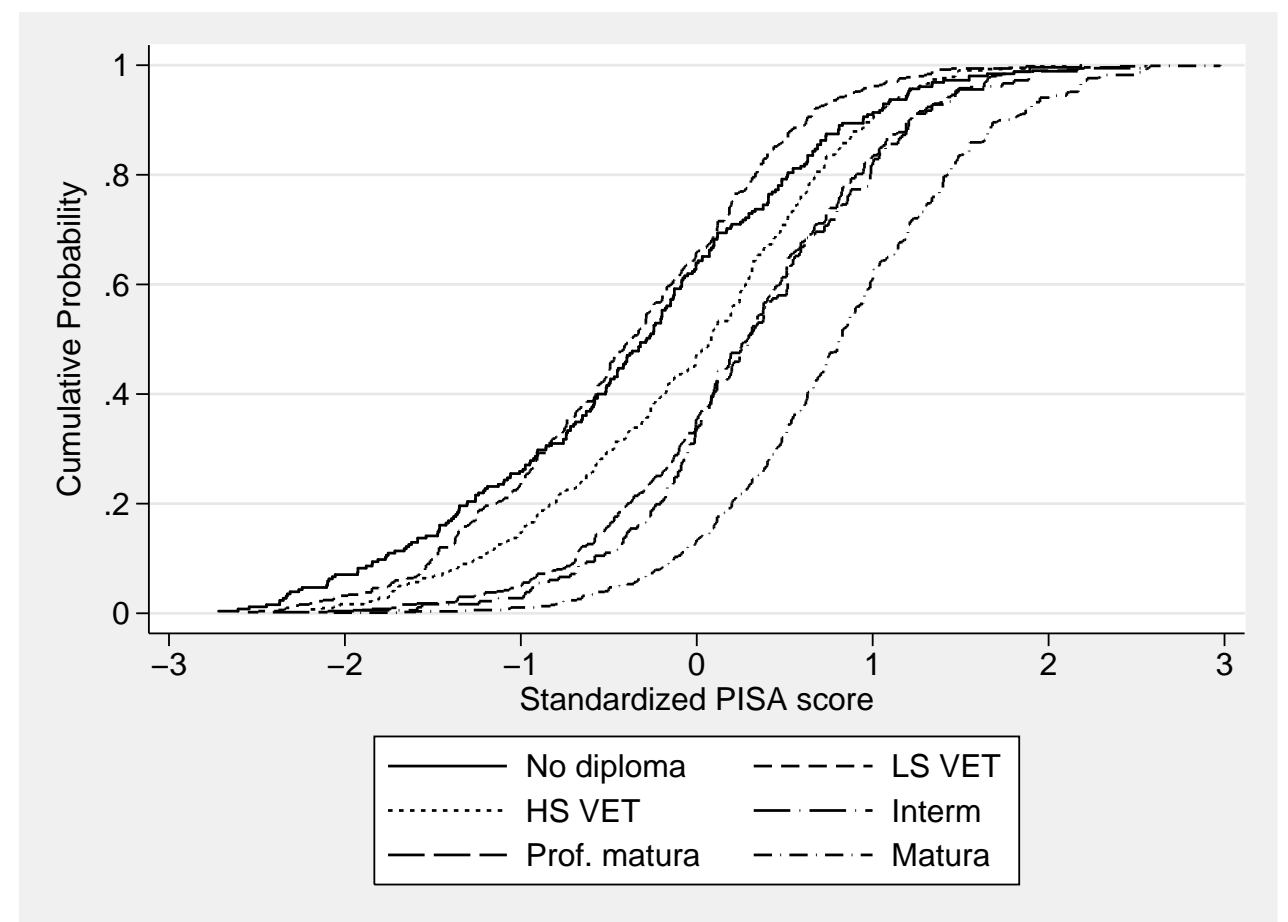

Figure 2: Cumulative distribution function of standardized PISA scores by obtained diploma

With respect to our dependent variable, it is worth showing how it relates to the PISA score. We present the empirical cumulative distribution function of the standardized PISA scores by the obtained diploma. As shown in Figure 2, the cumulative distribution of the PISA scores for people having achieved the matura has a clear first order dominance over the other diplomas. 
The same cannot be said between students having completed an intermediate schooling and those having achieved a professional matura as no clear-cut dominance emerges. However, the latter two first-order dominate the remaining diploma which are assumed to have lower value in our analysis. These are "high skilled VET", "low skilled VET" and "no diploma". High skilled VET graduates clearly first-order dominate low skilled VET graduates, which gives support to our distinction. Finally the distribution of those not having earned a degree is not so clear, since it is first-order dominated by all other distributions for low PISA scores but then first-order dominates low skilled VET. The general impression from this diagram is a plausible division across the different educational outcome levels. The only ambiguity from this diagram lies in a possible division between professional matura and intermediate school. Indeed, our justification is that the professional matura gives access to tertiary education, while intermediate school diploma alone does not.

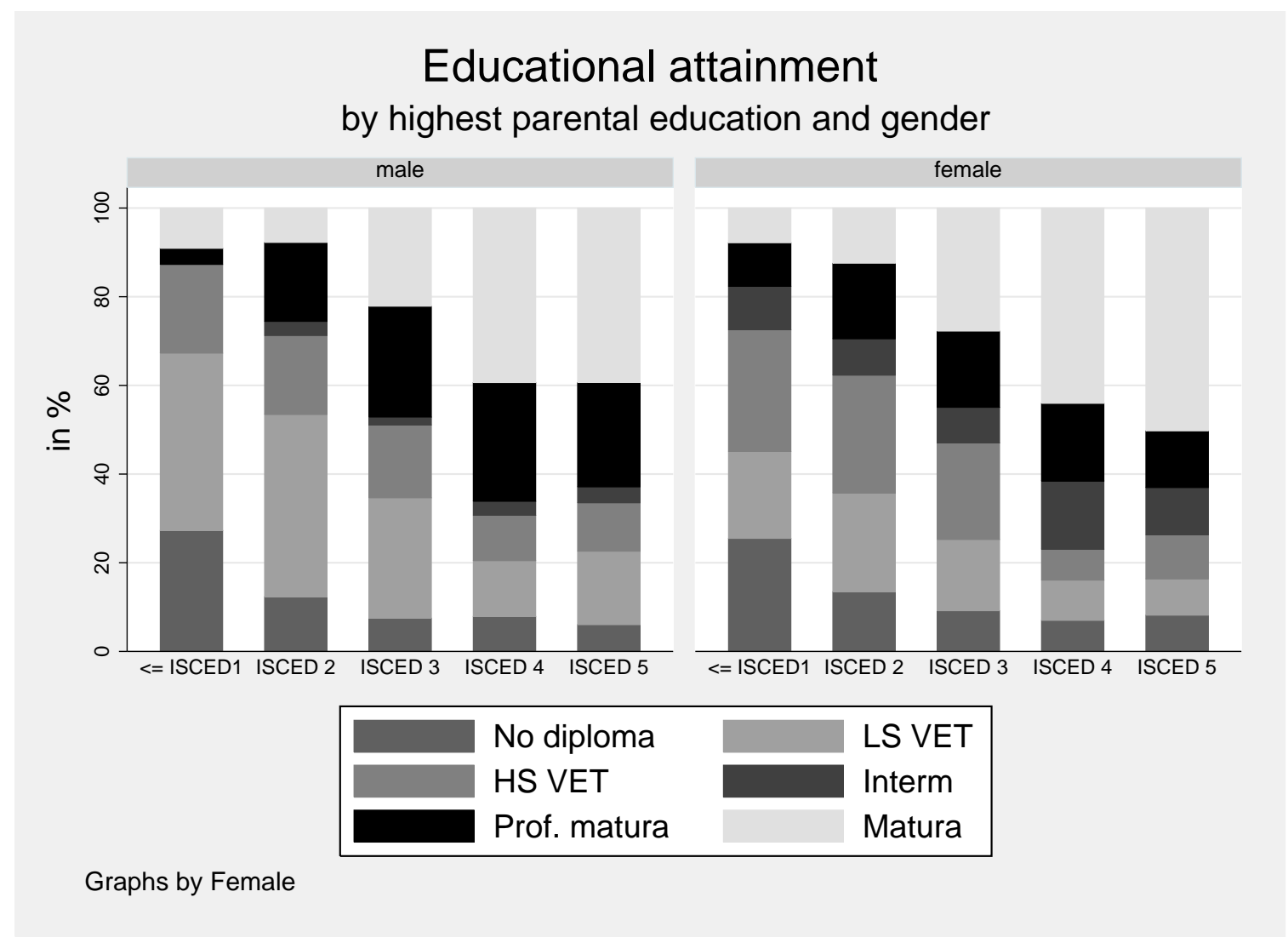

Figure 3: Distribution of diploma by highest parental education level (ISCED scale)

Figure 3 shows the relative diploma distribution according to the highest parental education level measured in the ISCED scale for both genders. A striking finding is that more than $20 \%$ of the children with very low-educated parents (ISCED 0 and ISCED 1) did not obtain a diploma. A finding that is equally valid for boys and girls. The share of people not having achieved any 
diploma dramatically falls when parental education improves.

When bundling together people with no diploma and people with only low skilled VET education, the proportion is slightly more than $60 \%$ for boys and slightly more than $40 \%$ for girls with low educated parents and only about $20 \%$ for children with highly educated parents.

On the other hand, the share of matura graduates grows from less than $10 \%$ to about $40 \%$ for boys and around $50 \%$ for girls. The chart clearly remains a very descriptive way of analyzing the relationship between parental education and children's achievements. The mechanism that brings about these results requires a more elaborate model to fully capture all its complexity.

\subsection{Econometric results}

Moving from a merely descriptive analysis to the econometric model allows a much deeper understanding. Table 3 presents the results of the bivariate ordered probit models displaying the estimated parameters for the whole sample, as well as for girls and boys separately. At this stage, the coefficients are not directly interpretable, yet they give much valuable information regarding the model. The discussion of marginal effects in section 5.2.1 will provide more intuitive findings.

The use of a bivariate ordered probit model is mostly motivated by the endogeneity of the first stage outcome in the second stage variable. Hence, the parameter $\gamma$ measuring this endogeneity should be analyzed first, as it indicates the contribution of the first stage latent variable on the second stage latent variable. The use of a bivariate ordered probit model will prove justified only if this contribution is significantly different from zero. If $\gamma$ is zero, the endogeneity problem would disappear and the model could be estimated by a simple ordered probit model. While the $\gamma$ parameter is significant and positive for the whole sample and for boys, it is not significant for girls. This suggests that, everything else constant, tracking in the first period does not affect the diploma in the upper secondary education for girls. Hence, all parental effects playing a role in the first stage outcome are not transferred to subsequent stages, and the playing field is level again for girls after the lower secondary school. The situation is substantially different for boys, for whom we find a large value for the $\gamma$ coefficient. The estimate shows that a one standard deviation change in the latent variable of the first stage is related to a 0.26 standard deviation change in the second stage latent variable. Even if in the second stage the parental background would have no direct impact, it would still show up with relatively strong indirect effect.

The $\rho$ correlation coefficient of the error terms is highly significant in all samples and so are all threshold estimators $(\mu)$. It also implies that the choice of a bivariate ordered probit model makes perfect sense in our context.

The first stage results do not exhibit large differences between male and female pupils in terms of significance levels. A positive coefficient should be interpreted as an effect towards highervalued education in the underlying variable. This will next be translated into a positive marginal 
Table 3: Bivariate ordered probit estimation

\begin{tabular}{|c|c|c|c|c|c|c|}
\hline & \multicolumn{2}{|l|}{ Full sample } & \multicolumn{2}{|l|}{ Girls } & \multicolumn{2}{|l|}{ Boys } \\
\hline \multicolumn{7}{|c|}{ First stage: track in in lower secondary education } \\
\hline Institution (2 tracks) & $0.713^{* * *}$ & $(0.113)$ & $0.736^{* * *}$ & $(0.141)$ & $0.679^{* * *}$ & $(0.181)$ \\
\hline Institution (4 tracks) & $-0.468^{* * *}$ & $(0.064)$ & $-0.335^{* * *}$ & $(0.086)$ & $-0.652^{* * *}$ & $(0.095)$ \\
\hline Institution (coop./integr.) & -0.076 & $(0.117)$ & -0.038 & $(0.149)$ & -0.134 & $(0.186)$ \\
\hline Prop. extended & $2.794^{* * *}$ & $(0.317)$ & $2.921^{* * *}$ & $(0.425)$ & $2.603^{* * *}$ & $(0.475)$ \\
\hline Rural area & $-0.461^{* * *}$ & $(0.085)$ & $-0.382^{* * *}$ & $(0.115)$ & $-0.556^{* * *}$ & $(0.122)$ \\
\hline First born & $0.179 * * *$ & $(0.057)$ & $0.160^{* *}$ & $(0.075)$ & $0.197^{* *}$ & $(0.086)$ \\
\hline Female & $0.126^{* * *}$ & $(0.045)$ & & & & \\
\hline Latin Switzerland & 0.090 & $(0.087)$ & 0.114 & $(0.116)$ & 0.067 & $(0.132)$ \\
\hline Parental educ. (ISCED 3) & $0.409^{* * *}$ & $(0.065)$ & $0.331^{* * *}$ & $(0.083)$ & $0.518^{* * *}$ & $(0.103)$ \\
\hline Parental educ. (ISCED 4) & $0.743^{* * *}$ & $(0.087)$ & $0.659^{* * *}$ & $(0.114)$ & $0.867^{* * *}$ & $(0.134)$ \\
\hline Parental educ. (ISCED 5+) & $0.654^{* * *}$ & $(0.064)$ & $0.591^{* * *}$ & $(0.086)$ & $0.745^{* * *}$ & $(0.096)$ \\
\hline $51-250$ books & $0.327 * * *$ & $(0.060)$ & $0.401^{* * *}$ & $(0.082)$ & $0.259^{* * *}$ & $(0.089)$ \\
\hline$>250$ books & $0.776^{* * *}$ & $(0.067)$ & $0.846^{* * *}$ & $(0.092)$ & $0.704^{* * *}$ & $(0.098)$ \\
\hline Born in $\mathrm{CH}$ & $0.386^{* * *}$ & $(0.083)$ & $0.452^{* * *}$ & $(0.115)$ & $0.322^{* * *}$ & $(0.121)$ \\
\hline \multicolumn{7}{|c|}{ Second stage: first upper secondary diploma } \\
\hline Latin Switzerland & $0.287^{* *}$ & $(0.139)$ & 0.230 & $(0.181)$ & $0.417^{* *}$ & $(0.210)$ \\
\hline Parental educ. (ISCED 3) & $0.240^{* * *}$ & $(0.060)$ & $0.259^{* * *}$ & $(0.077)$ & $0.196^{* *}$ & $(0.095)$ \\
\hline Parental educ. (ISCED 4) & $0.525^{* * *}$ & $(0.089)$ & $0.528^{* * *}$ & $(0.118)$ & $0.506^{* * *}$ & $(0.136)$ \\
\hline Parental educ. (ISCED 5+) & $0.575^{* * *}$ & $(0.061)$ & $0.606^{* * *}$ & $(0.082)$ & $0.524 * * *$ & $(0.095)$ \\
\hline $51-250$ books & 0.066 & $(0.052)$ & $0.143^{*}$ & $(0.074)$ & -0.004 & $(0.076)$ \\
\hline$>250$ books & $0.385^{* * *}$ & $(0.072)$ & $0.499 * * *$ & $(0.100)$ & $0.275^{* * *}$ & $(0.103)$ \\
\hline Born in $\mathrm{CH}$ & 0.094 & $(0.077)$ & 0.023 & $(0.114)$ & $0.210^{*}$ & $(0.108)$ \\
\hline Female & $0.122^{* * *}$ & $(0.044)$ & & & & \\
\hline Private school & 0.062 & $(0.120)$ & 0.012 & $(0.140)$ & 0.236 & $(0.209)$ \\
\hline Absence index & -0.010 & $(0.018)$ & -0.010 & $(0.024)$ & -0.010 & $(0.028)$ \\
\hline Effort index & $0.069^{* * *}$ & $(0.022)$ & $0.052^{*}$ & $(0.029)$ & $0.082^{* *}$ & $(0.032)$ \\
\hline Standardized PISA score & $0.197^{* * *}$ & $(0.030)$ & $0.190^{* * *}$ & $(0.041)$ & $0.213^{* * *}$ & $(0.045)$ \\
\hline Language grades & $0.151^{* * *}$ & $(0.036)$ & $0.161^{* * *}$ & $(0.047)$ & $0.151^{* * *}$ & $(0.057)$ \\
\hline Mathematics grades & $0.276^{* * *}$ & $(0.029)$ & $0.293^{* * *}$ & $(0.040)$ & $0.259 * * *$ & $(0.044)$ \\
\hline$\rho$ & $0.612^{* * *}$ & $(0.066)$ & $0.694^{* * *}$ & $(0.092)$ & $0.528^{* * *}$ & $(0.095)$ \\
\hline$\gamma$ & $0.151^{* *}$ & $(0.062)$ & 0.060 & $(0.083)$ & $0.264^{* * *}$ & $(0.091)$ \\
\hline$\mu_{11}$ & $1.939^{* * *}$ & $(0.233)$ & $1.925^{* * *}$ & $(0.305)$ & $1.812^{* * *}$ & $(0.354)$ \\
\hline$\mu_{12}$ & $3.391^{* * *}$ & $(0.242)$ & $3.419^{* * *}$ & $(0.317)$ & $3.224^{* * *}$ & $(0.365)$ \\
\hline$\mu_{21}$ & $2.960 * * *$ & $(0.866)$ & $3.062^{* *}$ & $(1.220)$ & $2.840^{* *}$ & (1.299) \\
\hline$\mu_{22}$ & $3.780^{* * *}$ & $(0.876)$ & $3.662^{* * *}$ & $(1.235)$ & $3.952 * * *$ & (1.307) \\
\hline$\mu_{23}$ & $4.346^{* * *}$ & $(0.883)$ & $4.269 * * *$ & $(1.251)$ & $4.471^{* * *}$ & (1.313) \\
\hline$\mu_{24}$ & $4.583^{* * *}$ & $(0.886)$ & $4.600^{* * *}$ & $(1.259)$ & $4.580^{* * *}$ & (1.314) \\
\hline$\mu_{25}$ & $5.281^{* * *}$ & $(0.895)$ & $5.154^{* * *}$ & $(1.273)$ & $5.481^{* * *}$ & (1.321) \\
\hline $\mathrm{N}$ & 2710 & & 1498 & & 1212 & \\
\hline$\chi_{(4)}^{2}$ & 349.01 & & 185.85 & & 165.59 & \\
\hline
\end{tabular}

Standard errors in parenthesis. Significance levels at $10 \%(*), 5 \%(* *)$ and $1 \%\left({ }^{* * *}\right)$. The $\chi^{2}$-statistic refers to the test of joint significance of the instruments in the first stage 
effect for high valued education and a negative marginal effect for the bottom level education. Generally the coefficients have the same sign and are more or less in the same range across samples. Family background variables such as parental education and the amount of books in the household all have positive effects on the first stage education. Interestingly, parental education has a greater effect on boys whereas a larger quantity of books at home affects more girls. Children born in Switzerland (i.e. natives and second generation migrants) have better chances to end up in a highly valued track than first generation migrants. All other things equal, living in a rural area increases the chances to end up in lower education levels.

All these first-stage effectswill also persist in the second stage through multiplication by the $\gamma$ coefficient. Besides this indirect effect, several direct effects were found, sometimes from the same regressors, corresponding to a reinforcing effect. In this sense, the dummy for Latin regions turns significant for boys. Parental education still matters and interestingly the direct effect on the second stage is now higher for girls than for boys, while the opposite was true for the first stage. As in the first stage, the quantity of books at home has a more sizeable effect for girls. Male first generation migrants seem to have again a disadvantage in the second stage, which is not true for their female counterparts.

Next, explanatory variables only included in the second step are also interesting. Being educated in a private school does not seem to matter at all which is surprising. The same is true for the absenteeism indicator provided in PISA. All remaining regressors are significant. Effort is positively associated with the upper secondary education outcome and the effect is slightly higher for boys. PISA scores and the grades at school all have positive and highly significant effects of the same size in both male and female samples.

\subsubsection{Marginal effects}

Marginal effects are the relevant estimates to gauge the quantitative effect of these variables. We compute marginal effects for each possible outcome in the second stage. Depending on the presence in both stages or not, one to two effects per regressors are given. This yields a relatively large amount of numerical results. However, due to the functional form of our model, there are some mechanical relationships between the effects of each regressor. By definition the marginal effect of the lowest outcome has always the opposite sign to the effect of the highest outcome. Middle range outcomes present smaller values in absolute terms. Bearing this in mind, we can focus the discussion on the marginal effect on the two extreme outcomes. A second advantage of the marginal effect representation is that we can directly compare the direct to the indirect effect, which is one of the core interests of this paper.

Tables 4 and 5 present the marginal effect on the second stage outcome for girls and boys respectively. The marginal effects we compute are average marginal effects as explained in section 3.2 and not marginal effects at the sample mean of all regressors. We prefer this way of 
Table 4: Estimated Marginal Effects for Girls

\begin{tabular}{|c|c|c|c|c|c|c|c|}
\hline Variable & Significance & Nothing & LS VET & HS VET & Interm. & Prof. Matura & Acad. Matura \\
\hline \multicolumn{8}{|l|}{ Latin Switzerland: } \\
\hline Direct: & & $-0.031^{+++}$ & $-0.022^{++}$ & -0.018 & -0.004 & 0.005 & $0.070^{+++}$ \\
\hline Indirect: & & $-0.001^{+++}$ & $-0.001^{++}$ & -0.000 & -0.000 & 0.000 & $0.002^{+++}$ \\
\hline \multicolumn{8}{|l|}{ Parental educ. (ISCED 3): } \\
\hline Direct: & $* * *$ & $-0.036^{+++}$ & $-0.024^{++}$ & -0.019 & -0.004 & 0.006 & $0.077^{+++}$ \\
\hline Indirect: & $* * *$ & $-0.003^{+++}$ & $-0.002^{++}$ & -0.001 & -0.000 & 0.001 & $0.006^{+++}$ \\
\hline \multicolumn{8}{|l|}{ Parental educ. (ISCED 4): } \\
\hline Direct: & $* * *$ & $-0.060^{+++}$ & $-0.048^{++}$ & -0.045 & -0.014 & 0.003 & $0.165^{+++}$ \\
\hline Indirect: & $* * *$ & $-0.006^{+++}$ & $-0.004^{++}$ & -0.003 & -0.001 & 0.001 & $0.012^{+++}$ \\
\hline \multicolumn{8}{|l|}{ Parental educ. (ISCED 5+): } \\
\hline Direct: & $* * *$ & $-0.080^{+++}$ & $-0.061^{++}$ & -0.051 & -0.011 & 0.015 & $0.187^{+++}$ \\
\hline Indirect: & $* * *$ & $-0.005^{+++}$ & $-0.003^{++}$ & -0.003 & -0.000 & 0.001 & $0.011^{+++}$ \\
\hline \multicolumn{8}{|l|}{ 51-250 books: } \\
\hline Direct: & * & $-0.021^{+++}$ & $-0.013^{++}$ & -0.010 & -0.002 & 0.004 & $0.042^{+++}$ \\
\hline Indirect: & $* * *$ & $-0.003^{+++}$ & $-0.002^{++}$ & -0.002 & -0.000 & 0.001 & $0.007^{+++}$ \\
\hline \multicolumn{8}{|l|}{$>250$ books: } \\
\hline Direct: & $* * *$ & $-0.064^{+++}$ & $-0.050^{++}$ & -0.044 & -0.011 & 0.011 & $0.157^{+++}$ \\
\hline Indirect: & $* * *$ & $-0.007^{+++}$ & $-0.005^{++}$ & -0.004 & -0.001 & 0.001 & $0.015^{+++}$ \\
\hline \multicolumn{8}{|l|}{ Born in $\mathrm{CH}$ : } \\
\hline Direct: & & $-0.003^{+++}$ & $-0.002^{++}$ & -0.002 & -0.000 & 0.001 & $0.007^{+++}$ \\
\hline Indirect: & $* * *$ & $-0.004^{+++}$ & $-0.003^{++}$ & -0.002 & -0.000 & 0.001 & $0.008^{+++}$ \\
\hline \multicolumn{8}{|c|}{ Second stage variables only } \\
\hline \multicolumn{8}{|l|}{ Private school: } \\
\hline Direct: & & $-0.002^{+++}$ & $-0.001^{++}$ & -0.001 & -0.000 & 0.000 & $0.003^{+++}$ \\
\hline \multicolumn{8}{|l|}{ Absence index: } \\
\hline Direct: & & $0.001^{+++}$ & $0.001^{++}$ & 0.001 & 0.000 & -0.000 & $-0.003^{+++}$ \\
\hline \multicolumn{8}{|l|}{ Effort index: } \\
\hline Direct: & * & $-0.007^{+++}$ & $-0.005^{++}$ & -0.004 & -0.001 & 0.001 & $0.015^{+++}$ \\
\hline \multicolumn{8}{|l|}{ Standardized PISA score: } \\
\hline Direct: & $* * *$ & $-0.025^{+++}$ & $-0.018^{++}$ & -0.015 & -0.004 & 0.003 & $0.058^{+++}$ \\
\hline \multicolumn{8}{|l|}{ Std. language grades: } \\
\hline Direct: & $* * *$ & $-0.014^{+++}$ & $-0.010^{++}$ & -0.008 & -0.002 & 0.002 & $0.031^{+++}$ \\
\hline \multicolumn{8}{|l|}{ Std. mathematics grades: } \\
\hline Direct: & $* * *$ & $-0.029^{+++}$ & $-0.022^{++}$ & -0.019 & -0.005 & 0.004 & $0.071^{+++}$ \\
\hline
\end{tabular}

Significance levels at ${ }^{+}=10 \%,{ }^{++}=5 \%$ and ${ }^{+++}=1 \%$ based on the empirical distribution

computing marginal effects since it allows to further analyze them with the goal of getting an even closer view.

When computing the marginal effects, one cannot take simply the significance level of the estimated coefficients, since the significance of marginal effects is not necessarily the same for all outcomes. As we compute the average marginal effects, we can easily compute the standard deviation over our observations which would allow us then to use a standard statistical test to evaluate the significance. However, the use of a student test for instance would yield to uninformative results that do not necessarily cover our objectives. Therefore we advocate for a more empirically based approach by computing the confidence interval based on the empirical distri- 
bution. The relatively large sample allows us to use the empirical percentiles to estimate the significance level. We therefore define a marginal effect to be "significantly" different from zero at the 0.95 level whenever $95 \%$ or more of the individual marginal effects have the same sign. To avoid confusion between our "quasi-significance" levels and the normally used significance levels, we denote them with the plus sign $(+)$ instead of the generally used stars $\left.{ }^{*}\right)$. In our view, this way of presenting the significance level of a marginal effect makes more sense, since a standard $t$-test refers to an average effect being statistically different from zero even though many individuals in the sample could face an opposite sign effect. It would not be wrong in a statistical sense, but it would not necessarily provide a precise answer to the questions we are interested in.

Table 5: Estimated Marginal Effects for Boys

\begin{tabular}{|c|c|c|c|c|c|c|c|}
\hline Variable & Significance & Nothing & LS VET & HS VET & Interm. & Prof. Matura & Acad. Matura \\
\hline \multicolumn{8}{|l|}{ Latin Switzerland: } \\
\hline Direct: & $* *$ & $-0.045^{+++}$ & $-0.057^{+}$ & -0.017 & -0.002 & 0.015 & $0.106^{+++}$ \\
\hline Indirect: & & $-0.002^{+++}$ & $-0.002^{+}$ & -0.001 & -0.000 & 0.001 & $0.004^{+++}$ \\
\hline \multicolumn{8}{|l|}{ Parental educ. (ISCED 3): } \\
\hline Direct: & $* *$ & $-0.023^{+++}$ & $-0.027^{+}$ & -0.007 & -0.001 & 0.008 & $0.049^{+++}$ \\
\hline Indirect: & $* * *$ & $-0.016^{+++}$ & $-0.019^{+}$ & -0.005 & -0.000 & 0.006 & $0.034^{+++}$ \\
\hline \multicolumn{8}{|l|}{ Parental educ. (ISCED 4): } \\
\hline Direct: & $* * *$ & $-0.049^{+++}$ & $-0.070^{++}$ & -0.024 & -0.003 & 0.011 & $0.134^{+++}$ \\
\hline Indirect: & $* * *$ & $-0.025^{+++}$ & $-0.032^{+}$ & -0.009 & -0.001 & 0.008 & $0.059^{+++}$ \\
\hline \multicolumn{8}{|l|}{ Parental educ. (ISCED 5+): } \\
\hline Direct: & $* * *$ & $-0.058^{+++}$ & $-0.076^{++}$ & -0.021 & -0.002 & 0.024 & $0.133^{+++}$ \\
\hline Indirect: & $* * *$ & $-0.023^{+++}$ & $-0.028^{+}$ & -0.007 & -0.001 & 0.009 & $0.049^{+++}$ \\
\hline \multicolumn{8}{|l|}{ 51-250 books: } \\
\hline Direct: & & $0.001^{+++}$ & $0.001^{+}$ & 0.000 & 0.000 & -0.000 & $-0.001^{+++}$ \\
\hline Indirect: & $* * *$ & $-0.008^{+++}$ & $-0.009^{+}$ & -0.002 & -0.000 & 0.003 & $0.017^{+++}$ \\
\hline \multicolumn{8}{|l|}{$>250$ books: } \\
\hline Direct: & $* * *$ & $-0.031^{+++}$ & $-0.040^{++}$ & -0.011 & -0.001 & 0.012 & $0.070^{+++}$ \\
\hline Indirect: & $* * *$ & $-0.021^{+++}$ & $-0.026^{+}$ & -0.007 & -0.001 & 0.008 & $0.047^{+++}$ \\
\hline \multicolumn{8}{|l|}{ Born in $\mathrm{CH}$ : } \\
\hline Direct: & * & $-0.027^{+++}$ & $-0.029^{+}$ & -0.006 & -0.000 & 0.012 & $0.050^{+++}$ \\
\hline Indirect: & $* * *$ & $-0.010^{+++}$ & $-0.012^{+}$ & -0.003 & -0.000 & 0.004 & $0.021^{+++}$ \\
\hline \multicolumn{8}{|c|}{ Second stage variables only } \\
\hline \multicolumn{8}{|l|}{ Private school: } \\
\hline Direct: & & $-0.025^{+++}$ & $-0.033^{+}$ & -0.010 & -0.001 & 0.008 & $0.061^{+++}$ \\
\hline \multicolumn{8}{|l|}{ Absence index: } \\
\hline Direct: & & $0.001^{+++}$ & $0.001^{+}$ & 0.000 & 0.000 & -0.000 & $-0.002^{+++}$ \\
\hline \multicolumn{8}{|l|}{ Effort index: } \\
\hline Direct: & $* *$ & $-0.009^{+++}$ & $-0.011^{+}$ & -0.003 & -0.000 & 0.003 & $0.020^{+++}$ \\
\hline \multicolumn{8}{|l|}{ Standardized PISA score: } \\
\hline Direct: & $* * *$ & $-0.023^{+++}$ & $-0.029^{+}$ & -0.009 & -0.001 & 0.007 & $0.055^{+++}$ \\
\hline \multicolumn{8}{|l|}{ Std. language grades: } \\
\hline Direct: & $* * *$ & $-0.011^{+++}$ & $-0.013^{+}$ & -0.004 & -0.000 & 0.004 & $0.024^{+++}$ \\
\hline \multicolumn{8}{|l|}{ Std. mathematics grades: } \\
\hline Direct: & $* * *$ & $-0.022^{+++}$ & $-0.028^{+}$ & -0.008 & -0.001 & 0.007 & $0.052^{+++}$ \\
\hline
\end{tabular}

Significance levels at ${ }^{+}=10 \%,{ }^{++}=5 \%$ and ${ }^{+++}=1 \%$ based on the empirical distribution 
Parental education and the number of books at home present a very interesting pattern. For girls, the direct effect largely dominates the indirect effect, while they are almost equally important for boys. The total effect (as measured by their sum) is again very similar with somewhat larger marginal effects for girls. This result suggests that parental education matters for boys during the whole secondary education period, while the effect becomes more important for girls in upper secondary education. Boys and girls with very highly educated parents have up to $19 \%$ better chances to earn a matura degree than children with lowly-educated parents (the reference group). In other words, the odds of finishing school without any upper secondary degree is reduced by up to $8 \%$ for children with very well educated parents. Considering a certain correlation between parental education and the amount of books at home, it is easily imaginable that the true effect is even slightly higher.

As PISA scores and school grades were all normalized to unit variance, the marginal effects are directly comparable. A one standard deviation increase in PISA scores increases the likelihood of achieving the matura by about $5.5 \%$ for boys and $5.8 \%$ for girls. The same increase in mathematics' grades would raise the likelihood by $5.2 \%$ and $7.1 \%$ for boys and girls respectively. A glance at the other variables indicates that students in Latin regions are up to $10 \%$ (for boys) more likely to finish with a matura degree and about $5 \%$ less likely to finish with only a low skilled VET comparing to students in the German speaking part of Switzerland. The disadvantage of first generation migrants appears as both direct and indirect effects.

The means of marginal effects are given in Tables 4 and 5, but marginal effects can also be plotted against some variables like the cognitive skills' level of a child. Using kernel-weighted local polynomial smoothing, it is possible to visualize the marginal effects as a function of the PISA score. Figures 4 and 5 illustrate the marginal effects of very high parental education and PISA scores as a function of the PISA scores. In all diagrams, the effects for girls are plotted in black, while the ones for boys are in gray. The direct effects are depicted with a solid line and indirect effects with a dashed line.

Figure 4 shows the marginal effects of very high parental education (ISCED $5+$ ) on each of the six possible outcomes. Starting from the upper left panel corresponding to not achieving any upper secondary degree, it can be seen that the direct effects are more important all along the PISA distribution for both boys and girls. The effects are relatively more important for less skilled children and also more important for girls than for boys (irrespective of the PISA score). The upper right panel represents the marginal effects on finishing with only a low skill VET. The direct effects are more important than the indirect with the highest impact for average skilled children. Total marginal effects are more important for boys than for girls, especially for more skilled boys.

For high skilled VET, intermediate schools and professional matura, the highest parental education level has a positive impact on the lowest skilled children but a negative one on more skilled 

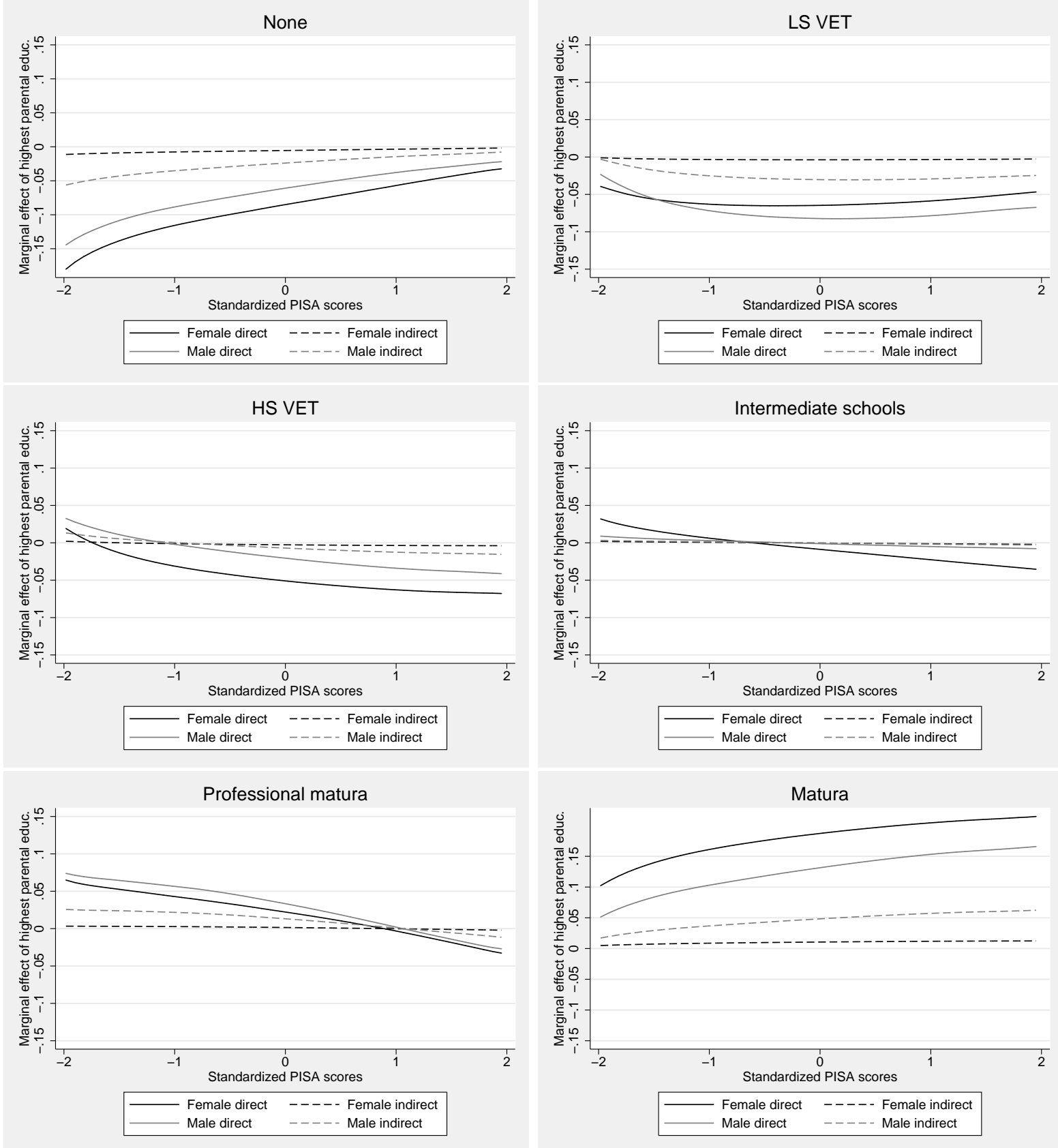

Note: PISA score distribution is truncated to \pm 2 standard deviations

Figure 4: Marginal effects of high parental education

children. Again, direct effects are more important all along the PISA distribution. Positive and along the PISA score increasing marginal effects of highest parental education are found for the normal matura. The effect for girls depends essentially on the direct effect, while boys benefit from very high parental education indirectly and directly in about the same proportions.

Figure 5 might be somewhat confusing at first glance. We plot the marginal effect of the PISA score against the PISA score itself in order to detect whether a given increase in cognitive scores 
affects schooling outcomes differently depending on the initial cognitive score. Again, starting from the upper left panel (which corresponds to the lowest possible educational outcome), the marginal effects are negative and become smaller along the PISA distribution. This implies that an increase in the cognitive score has much larger effects in the risk reduction of not getting a degree for low-skill students. For the most skilled students, an additional unit of cognitive skills will only have a small impact on reducing the odds of not earning any degree. Notice also that the effect for girls is roughly similar to the one for boys. An increase in the PISA score also reduces the risk of finishing with only a low skill VET, but the effect for boys is now more important. Moreover, the largest effect of an increase in the PISA score is observed for average skilled pupils, while low-skills and high-skills students would benefit less.

For the middle range outcomes, a positive effect is found for the least skilled ones and an increasingly negative effect for high-score students. This means that the lowly-skilled students can attain such an intermediate outcome (and avoid a lower outcome) thanks to a slight increase in their cognitive skills, whence the positive effect. More skilled students can jump to the next higher educational level (matura) thanks to an increase in their PISA score, whence a negative marginal effect. Finally the likelihood of getting the matura is always positively associated to the PISA score and the marginal effect is increasing along the PISA score. For the absolutely highest-score students the marginal effect appear to decline somewhat, which could be due to their very high probability of earning a matura anyway. In that case, a further increase in their score would no longer help them much.

\subsubsection{Gender differences}

Figure 6 gives a brief summary of some main findings of this paper and highlights gender differences. The direct and the indirect effect of several family background variables are illustrated. The total size of the bar corresponds to the total effect, while the indirect and the direct effects are respectively the dark-gray and light-gray components. The figure is informative in several ways. First, one can easily compare the relative strength of the most important determinants. Second, it is quite easy to spot which of the indirect or the direct effect matters most. It appears quite conclusively that children from very well educated parents (ISCED 4 or ISCED $5+$ ) have an advantage over the others. The effect is made up of two equally important direct and indirect effects for boys while the direct effect predominates for girls. Investigating thoroughly these gender differences is beyond the scope of this paper, but some tentative explanations can be put forth. The indirect effects cover transitions at age 15, when young people have to choose between vocational and general education. In our data, we find high level of occupational segregation between women and men pursuing an apprenticeship ${ }^{8}$. It appears therefore quite likely that the selection process greatly differs between boys and girls because of different vocational

\footnotetext{
${ }^{8}$ Depending on occupation coding, the Gini segregation index is around 0.70.
} 

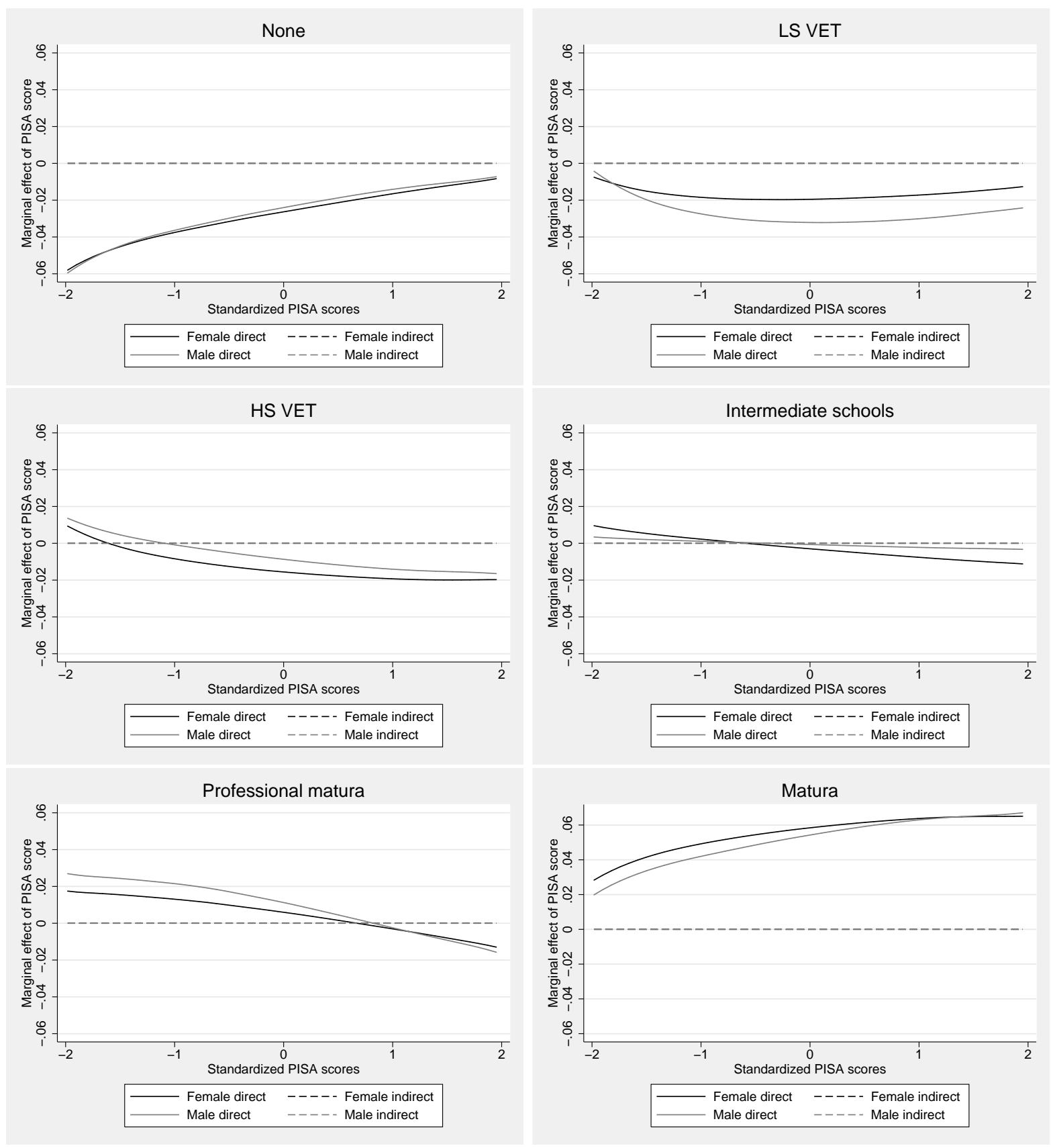

Note: PISA score distribution is truncated to \pm 2 standard deviations

Figure 5: Marginal effects of cognitive ability (reading)

education opportunities. This interpretation is vindicated by our results on the impact of the PISA score on educational outcomes (see 5.2.1, Figure 5). Indeed, marginal effects towards VET or the Matura are somewhat greater for females, which points to lower opportunities for high skilled girls in VET. Nevertheless, total marginal effects related to parental background which are the sum of direct and indirect effects are roughly similar across boys and girls. Hence, a sizeable impact of early tracking does not necessarily lead to higher educational inequalities. 


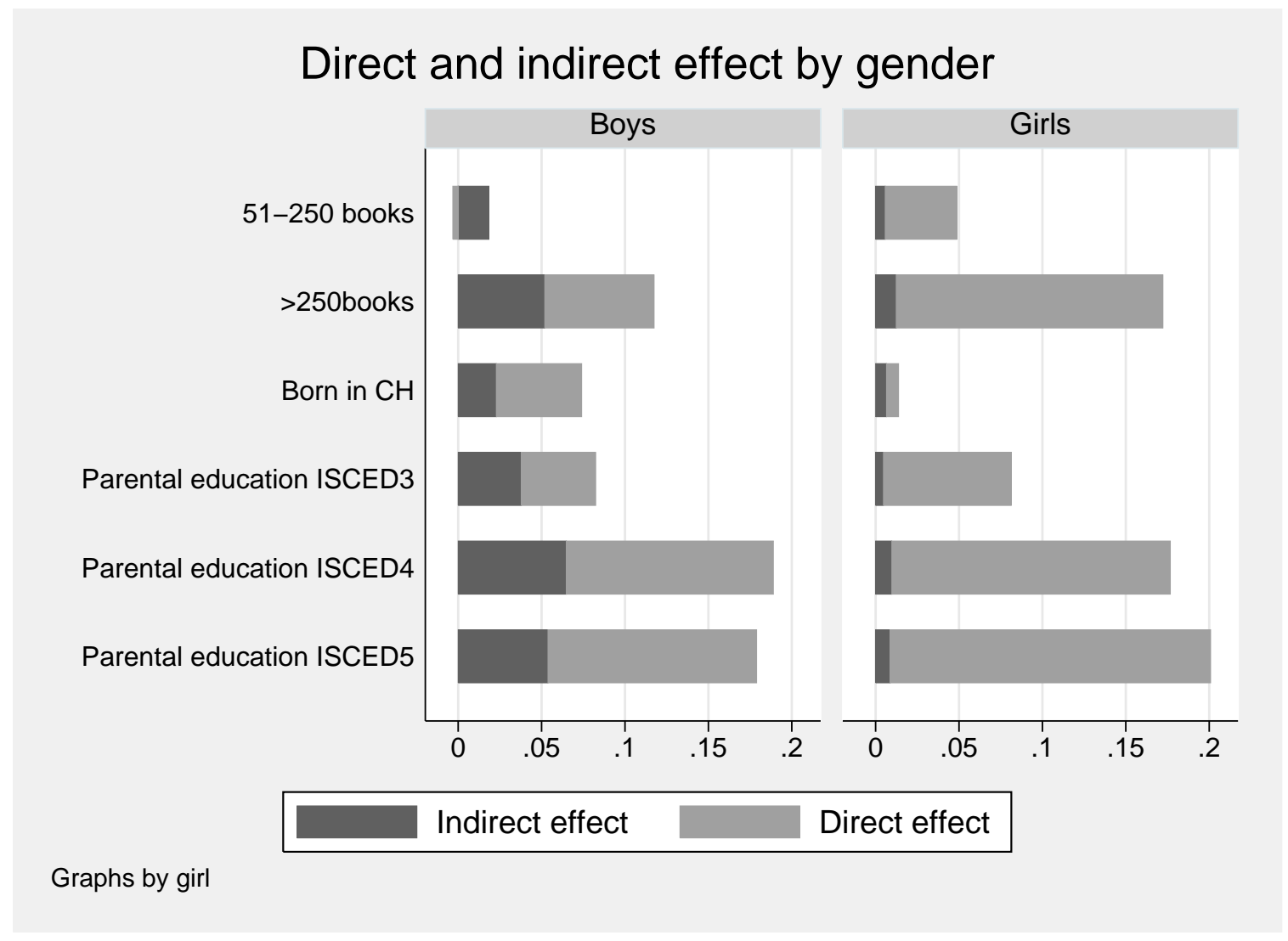

Figure 6: Direct and indirect effects by gender

A policy aiming at reducing inequality of opportunities related to high parental education should focus on the whole period of education when dealing with boys, while putting special emphasis on the secondary education period when dealing with girls. In general, direct effects are more important for girls and therefore policy measures designed for girls should take this difference into account. For both genders, and as shown by Cameron and Heckman (1998), the relatively large impact of direct effects outline the high persistence of parental background up to higher grade levels.

\section{Conclusion}

Our analysis aimed at identifying the impact of family background on educational outcomes. We contribute to the literature on school tracking by estimating a two-stage model to measure the cumulative impact of parental background on tracking at lower secondary education as well as on upper secondary school achievements. We can also partially control for usually unobserved factors by a proxy of unobserved ability. As expected, our results show large parental effects on upper secondary school achievements. For boys, these effects are equally split between indirect 
effects i.e. those stemming from lower secondary school tracking and direct effects which take place at upper secondary levels. For girls, the picture is somewhat different as direct effects are larger while total effects are roughly similar as those observed for males. Our explanation for these gender differences lie in the quantitative importance of the vocational education system, which provides less opportunities for females, thus postponing their selection. Our results also show that family background effects are still important at higher grade levels, even in a country where selection takes place early and after controlling for cognitive ability. 


\section{References}

Bauer, Philipp and Regina Riphahn, "Heterogeneity in the intergenerational transmission of educational attainment: evidence from Switzerland on natives and second-generation immigrants," Journal of Population Economics, 2007, 20, 121-148.

_ and Regina T. Riphahn, "Timing of school tracking as a determinant of intergenerational transmission of education," Economics Letters, 2006, 91 (1), 90 - 97.

Behrman, Jere R. and Mark R. Rosenzweig, "Does Increasing Women's Scholing Raise the Schooling of the Next Generation?," American Economic Review, 2002, 92 (1), 323-334.

Bertschy, Kathrin, M. Alejandra Cattaneo, and Stefan C. Wolter, "PISA and the Transistion into the Labour Market," LABOUR, 2009, 23 (Special Issue), 111-137.

Black, Sandra E. and Paul J. Devereux, "Recent Developments in Intergenerational Mobility," in "Handbooks in Economics - Handbook of Labor Economics, Vol 4B," Elsevier, 2011, pp. $1487-1541$.

Cameron, Stephen and James J. Heckman, "Life Cycle Schooling and Dynamic Selection Bias: Models and Evidence for Five Cohorts of American Males," Journal of Political Economy, 1998, 106 (2).

Cattaneo, Alejandra, Sandra Hanslin, and Rainer Winkelmann, "The Apple Falls Increasingly Far: Parent-Child Correlation in Schooling and the Growth of Post-Secondary Education in Switzerland," Swiss Journal of Economics and Statistics (SJES), June 2007, 143 (II), 133-153.

Dustmann, Christian, "Parental background, secondary school track choice, and wages," Oxford Economic Papers, April 2004, 56 (2), 209-230.

EDK, "The Swiss Education System," Swiss Conference of Cantonal Ministers of Education (EDK) www. edk.ch 2009.

Falter, Jean-Marc, Giovanni Ferro Luzzi, and Federica Sbergami, "The Effect of Parental Background on Track Choices and Wages," forthcoming in Swiss Journal of Economics and Statistics, vol 147, no. 22011.

Greene, Wiliam H., Econometric Analysis, 6 ed., Pearson - Prentice Hall, Upper Saddle River, New Jersey, 2008.

Hanushek, Eric and Ludger Woessman, "Does Education Tracking Affect Performance and Inequality? Differences in Differences Evidence Across Countries," The Economic Journal, 2006, 116, C63-C76. 
Holmund, Helena, Mikael Lindahl, and Erik Plug, "The Causal Effect of Parents' Schooling on Children's Schooling: A Comparison of Estimation Methods," Journal of Economic Literature, 2011, 49 (3), 615-651.

Lauer, Charlotte, "Family background, cohort and education: A French-German comparison based on a multivariate ordered probit model of educational attainment," Labour Economics, 2003, 10, 231-251.

OECD, "Education at a Glance," OECD Indicators 2002. OECD, Paris 2002.

_ , "OECD Economic Surveys Switzerland," OECD: Paris 2009.

Roemer, John E., Equality of Opportunity, Harvard University Press, Cambridge, 1998.

Rossler, Claudia Zahner, "PISA 2003: Kompetenzen fï $\frac{1}{2} \mathrm{r}$ die Zukunft, Zweiter nationaler Bericht," Bundesamt fi $i \frac{1}{2}$ r Statistik (BFS),Neuchï $i \frac{1}{2}$ tel 2005.

Schütz, Gabriela, Heinricht W. Ursprung, and Ludger Wössmann, "Education Policy and Equality of Opportunity," KYKLOS, 2008, 61 (2), 279-308.

Sen, Anindya and Anthony Clemente, "Intergenerational correlations in educational attainment: Birth order and family size effects using Canadian data," Economic of Education Review, 2010, 29 (1), 147-155.

Sjaia, Zurab, "Maximum likelihood estimation of a bivariate ordered probit model: implementation and Monte Carlo simulations," Working paper under submission for The Stata Journal 2008 .

Solon, Gary, "A model of intergenerational mobility variation over time and place," in Miles Corak, ed., Generational income mobility in North America and Europe, Cambridge University Press: Cambridge, 2004, pp. 38-47.

Stalder, B.E., "Das intellektuelle Anforderungsniveau von 107 Berufslehren," TREE: Bern 2005 .

van Elk, Roel, Marc van der Steeg, and Dinand Webbink, "Does the timing of tracking affect higher education completion?," Economics of Education Review, 2011, 30 (5), 10091021. 


\section{A Graphics related to the choice of the instrument}

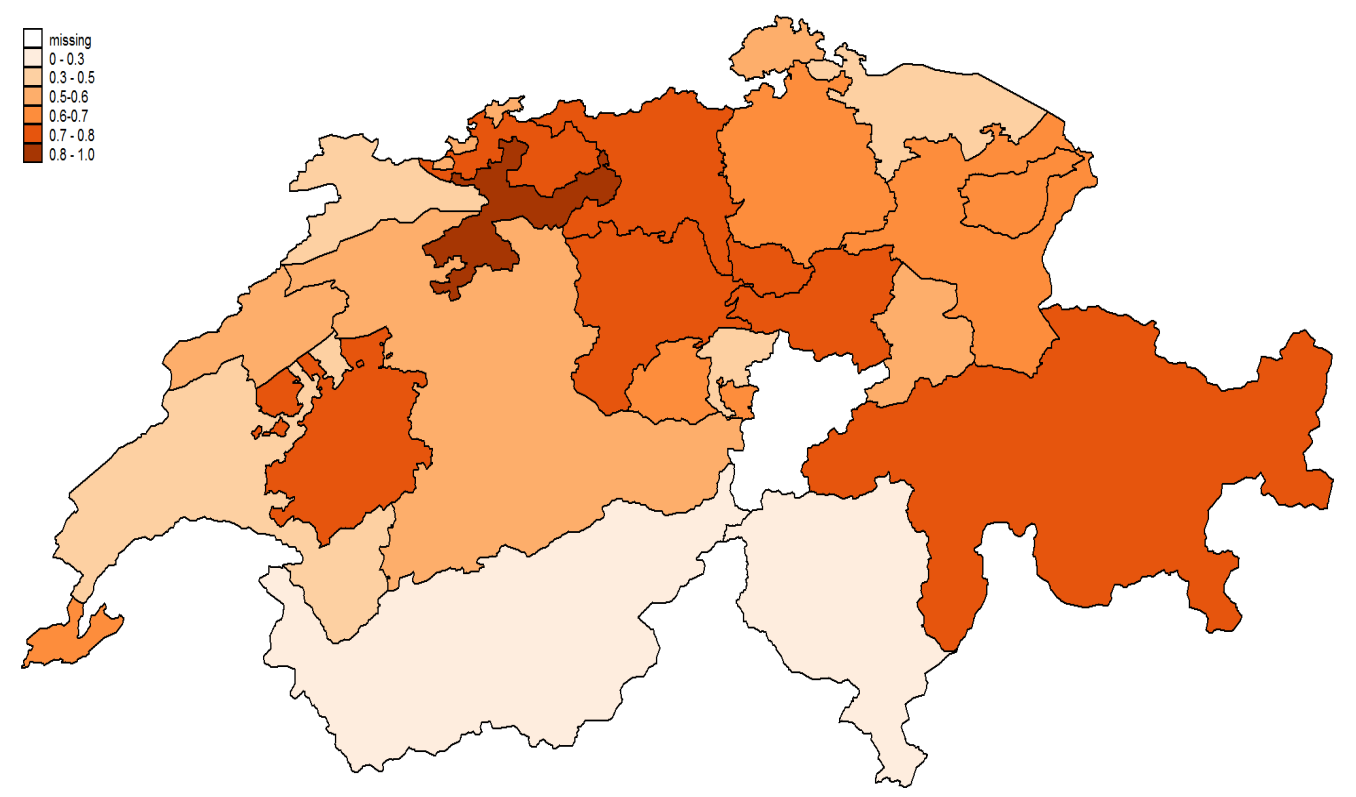

Figure 7: Geographical distribution of the share of students in the extended requirements track 


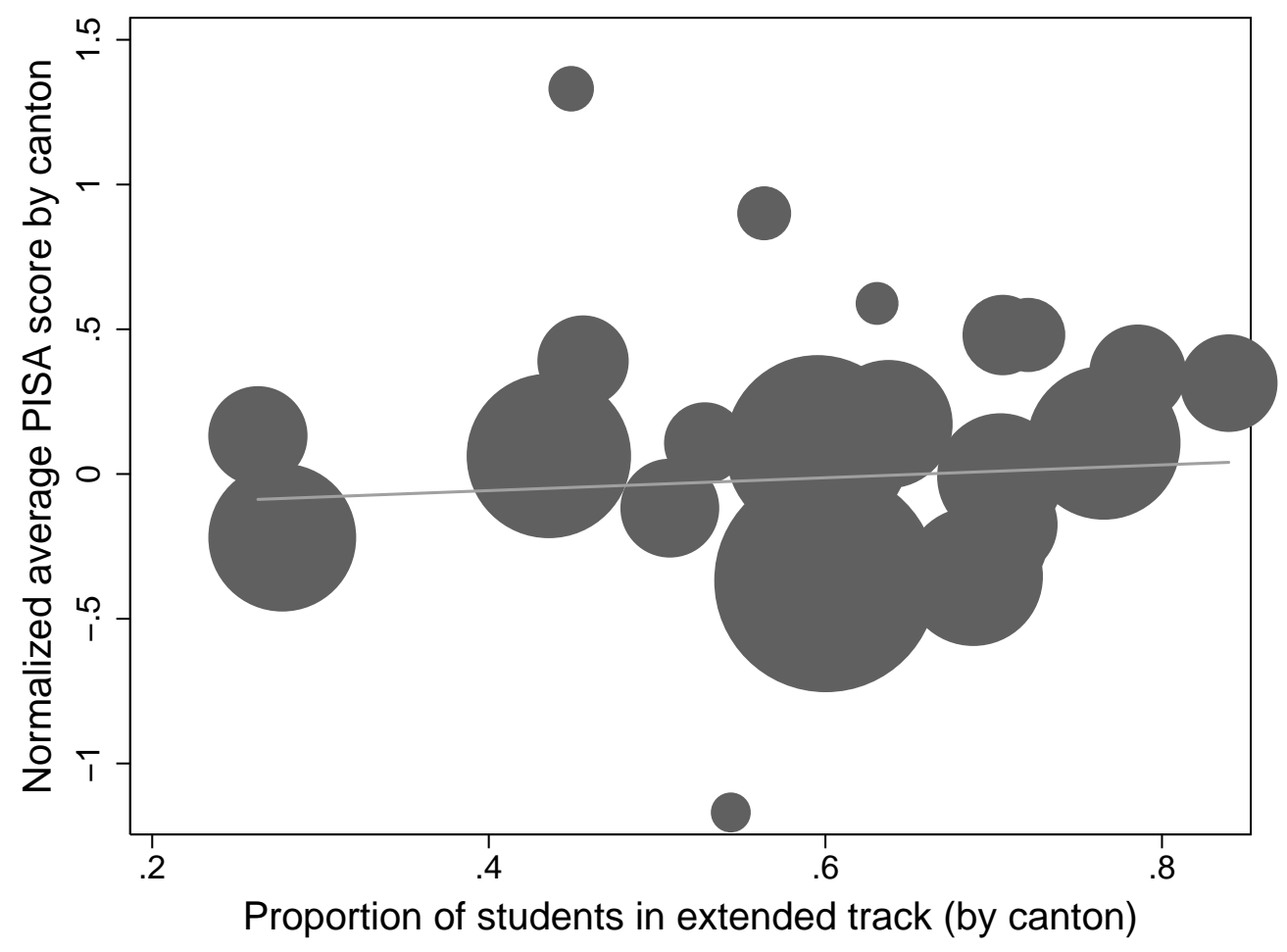

Figure 8: Relationship between PISA scores and the share of students in the extended requirements track 


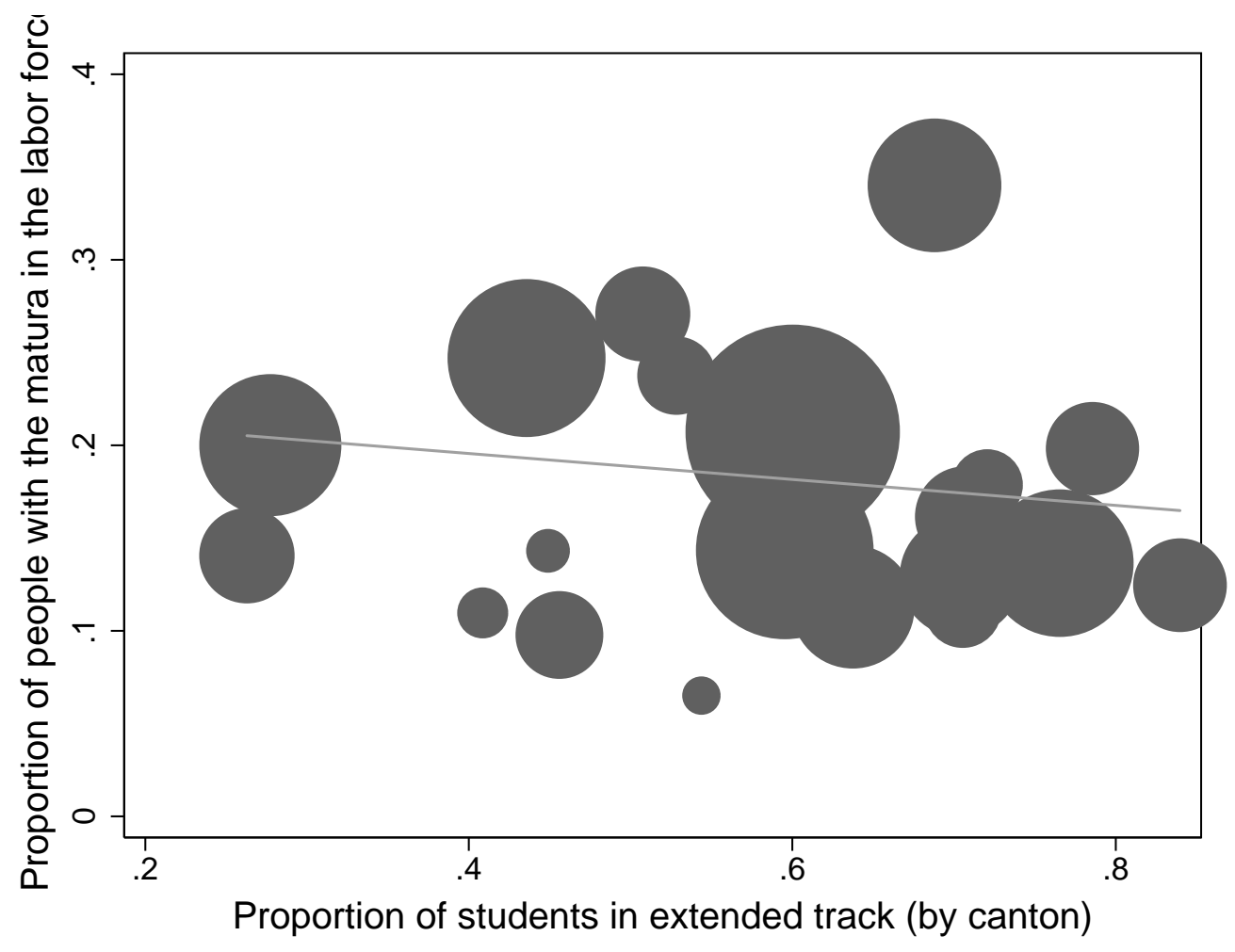

Figure 9: Relationship between share of people with the matura degree in the labor force and the share of students in the extended requirement tracks. 